\title{
Basal ganglia dysfunction in OCD: subthalamic neuronal activity correlates with symptoms severity and predicts high-frequency stimulation efficacy
}

\author{
M-L Welter ${ }^{1,2,3,4,5}$, P Burbaud $^{6,7}$, S Fernandez-Vidal ${ }^{1,8}$, E Bardinet $^{1,8}$, J Coste $^{9}$, B Piallat $^{10}$, M Borg $^{11}$, S Besnard $^{12}$, P Sauleau ${ }^{13}$, B Devaux $^{14}$, \\ B Pidoux ${ }^{15}$, P Chaynes $^{16}$, S Tézenas du Montce ${ }^{17}$, A Bastian ${ }^{1,2,3,4}$, N Langbour $^{6}$, A Teillant ${ }^{1,2,3,4}$, W Haynes ${ }^{1,2,3,4}$, J Yelnik ${ }^{1,2,3,4}$, \\ C Karachi ${ }^{1,2,3,4,18}$ and L Mallet ${ }^{1,2,3,4}$, for the French 'Stimulation dans le Trouble Obsessionnel Compulsif (STOC)' Study Group ${ }^{19}$
}

Functional and connectivity changes in corticostriatal systems have been reported in the brains of patients with obsessivecompulsive disorder (OCD); however, the relationship between basal ganglia activity and OCD severity has never been adequately established. We recently showed that deep brain stimulation of the subthalamic nucleus (STN), a central basal ganglia nucleus, improves OCD. Here, single-unit subthalamic neuronal activity was analysed in 12 OCD patients, in relation to the severity of obsessions and compulsions and response to STN stimulation, and compared with that obtained in 12 patients with Parkinson's disease (PD). STN neurons in OCD patients had lower discharge frequency than those in PD patients, with a similar proportion of burst-type activity (69 vs $67 \%$ ). Oscillatory activity was present in 46 and $68 \%$ of neurons in OCD and PD patients, respectively, predominantly in the low-frequency band (1-8 Hz). In OCD patients, the bursty and oscillatory subthalamic neuronal activity was mainly located in the associative-limbic part. Both OCD severity and clinical improvement following STN stimulation were related to the STN neuronal activity. In patients with the most severe OCD, STN neurons exhibited bursts with shorter duration and interburst interval, but higher intraburst frequency, and more oscillations in the low-frequency bands. In patients with best clinical outcome with STN stimulation, STN neurons displayed higher mean discharge, burst and intraburst frequencies, and lower interburst interval. These findings are consistent with the hypothesis of a dysfunction in the associativelimbic subdivision of the basal ganglia circuitry in OCD's pathophysiology.

Translational Psychiatry (2011) 1, e5; doi:10.1038/tp.2011.5; published online 3 May 2011

\section{Introduction}

Obsessive-compulsive disorder (OCD) is a common disabling disease, but its neural substrate remains poorly understood. A large set of imaging and neurophysiological data obtained in OCD patients have suggested, however, a dysfunction of the ventromedial corticosubcortical loop. ${ }^{1-9}$ In the light of these results, deep brain stimulation (DBS) of the caudate nucleus and adjacent structures has been proposed for the treatment of severe and refractory OCD patients. ${ }^{10-15}$ Recently, the subthalamic nucleus (STN) has appeared as another potential target for DBS following serendipitous results from Parkinson's disease (PD) patients ${ }^{16-18}$ and its role in associative and limbic information processing in human and non-human primates. ${ }^{19-21}$ Data obtained in rats and human also suggest that the STN is implicated in the ability to stop or inhibit an already initiated response, highlighting its potential role in impulse control disorders. ${ }^{22,23}$ We have recently confirmed the efficacy of stimulation applied in the medial part of the STN in OCD patients with a multicentre clinical trial. ${ }^{24}$ The usefulness of STN stimulation has also been investigated in rats and monkeys with induced compulsive-like behaviour. ${ }^{25-28}$ The fact that modulation of the STN neuronal activity by DBS improves OCD symptoms suggests that this basal ganglia structure may be dysfunctional in human patients.

\footnotetext{
${ }^{1}$ Centre de Recherche de I'Institut du Cerveau et de la Moelle épiniere (CRICM), Université Pierre et Marie Curie-Paris 6, UMR-S975, Paris, France; ${ }^{2}$ Inserm, U975, Paris, France; ${ }^{3} \mathrm{CNRS}$, UMR 7225, Paris, France; ${ }^{4}$ Groupe Hospitalier Pitié-Salpêtrière, Assistance Publique-Hôpitaux de Paris Centre d'Investigation Clinique, Paris, France; ${ }^{5}$ Groupe Hospitalier Pitié-Salpêtrière, Assistance Publique-Hôpitaux de Paris, Département de Neurologie, Bâtiment Paul Castaigne, Paris, France; ${ }^{6}$ Laboratoire Mouvement, Adaptation, Cognition, CNRS UMR 5227, Université Victor Segalen Bordeaux 2, Bordeaux, France; ${ }^{7}$ Service de Neurophysiologie, Hôpital Universitaire Pellegrin, Bordeaux, France; ${ }^{8}$ Groupe Hospitalier Pitié-Salpêtrière, Centre de Neuroimagerie de Recherche (CENIR), Paris, France; ${ }^{9}$ Service de Neurochirurgie A, CHU Clermont-Ferrand, Clermont-Ferrand, France; ${ }^{10}$ INSERM, U836, Grenoble Institute of Neuroscience, Grenoble, France; ${ }^{11}$ Service de Neurologie, CHU Nice, Nice, France; ${ }^{12}$ Service de Neurophysiologie Clinique, CHU Poitiers, Poitiers, France; ${ }^{13}$ Service de Neurophysiologie, CHU Rennes, Rennes, France; ${ }^{14}$ Service de Neurochirurgie, Hôpital Sainte-Anne, Paris, France; ${ }^{15}$ Groupe Hospitalier Pitié-Salpêtrière, Assistance Publique-Hôpitaux de Paris, Service de Neurophysiologie Clinique, Paris, France; ${ }^{16}$ Service de Neurochirurgie, CHU Toulouse, Toulouse, France; ${ }^{17}$ Groupe Hospitalier Pitié-Salpêtrière, Assistance PubliqueHôpitaux de Paris, Département de Biostatistiques et Information Médicale, ER4 (ex EA3974) Modélisation en Recherche Clinique, Paris, France and ${ }^{18}$ Groupe Hospitalier Pitié-Salpêtrière, Assistance Publique-Hôpitaux de Paris, Service de Neurochirurgie, Paris, France

Correspondence: Dr ML Welter, Groupe Hospitalier Pitié-Salpêtrière, Assistance Publique-Hôpitaux de Paris, Département de Neurologie, Bâtiment Paul Castaigne, 47-83 bd de l'Hôpital, Paris 75013, France.

E-mail: marie-laure.welter@psl.aphp.fr

${ }^{19}$ Members of the French STOC Study Group are listed in the Appendix.

Keywords: subthalamic nucleus; neuronal activity; obsessive-compusive disorders; Parkinson's disease; deep brain stimulation

Received 29 March 2011; accepted 1 April 2011
} 
One way to understand the potential role of the basal ganglia system and its dysfunction in OCD symptoms is to investigate subcortical structures electrophysiologically. Neuronal recordings of the striatum have already been reported in three OCD patients where an increased and more irregular pattern was found during obsessions. ${ }^{29}$ As the STN is the main target for DBS in patients with Parkinson's disease (PD), a large set of electrophysiological data have been reported in patients and non-human primate models of $P D$, and consistently show increased neuronal activity, occurrence of bursts, synchrony and oscillations. ${ }^{30-34}$ In such patients, an electrophysiological analysis has allowed, at least in part, to understand how STN dysfunction is linked to the motor symptoms ${ }^{33,35}$ and how these electrophysiological characteristics are related to the clinical outcome of STN stimulation. ${ }^{36,37}$ In OCD patients, compared with PD patients, the firing rate of subthalamic neurons has been shown to be lower with, however, the same proportion of bursting neurons. ${ }^{38}$

This study aimed to further explore the relationship between STN neuronal activity and OCD symptoms. Subthalamic electrophysiological recordings were obtained in OCD patients during surgery for DBS and analysed in relation to both OCD severity and STN stimulation outcome. ${ }^{24}$ Subthalamic neuronal activity recorded in PD patients operated under the same conditions was used for comparison. Previous studies led us to hypothesise that (1) subthalamic neuronal activity would be differentially affected in OCD compared with PD patients, especially in the ventromedial (associative-limbic) subdivision; and (2) the neuronal activity characteristics would be linked to clinical severity or response to STN stimulation of OCD symptoms.

\section{Materials and methods}

Participants. A total of 12 patients with severe and refractory OCD and 12 patients with severe form of $P D$ were included in this study. Patients with OCD were operated for bilateral high-frequency STN stimulation in a therapeutic trial (ClinicalTrials.gov number, NCT00169377) ${ }^{24}$ (see Supplementary Material and Table S1). All patients gave informed written consent and the protocol was approved by the local ethics committee. Patients with PD were operated for bilateral STN stimulation as routinely performed in our centre $^{39}$ (see Supplementary Material). None of the patients showed contraindication to surgical procedure, dementia or abnormal brain imaging.

Neurosurgical procedure. The surgery was performed as described previously. ${ }^{24,40}$ Briefly, the implantation of bilateral stimulating electrodes (Medtronic, model 3389, Minneapolis, MN, USA) was performed the same day using both preoperative anatomical and perioperative electrophysiological targeting. Subthalamic nuclei were preoperatively targeted by means of stereotactic magnetic resonance imaging, with additional ventriculography in some OCD patients (depending on the local protocol). ${ }^{24}$ In OCD patients, the target was defined $2 \mathrm{~mm}$ anterior and $1 \mathrm{~mm}$ medial to the PD target at the boundary of STN associative and limbic subdivisions. ${ }^{41,42}$
Micro-electrode recordings. Perioperative electrophysiological recordings were performed in awake patients, at rest (see Supplementary Material). Drug treatment was discontinued the evening before surgery in all patients. Extracellular single-unit neuronal activity was recorded simultaneously from 3 to 5 leads, used to identify and localise the STN for $2 \mathrm{~min}$ at rest, each $200-500 \mu \mathrm{m}$ within the STN. ${ }^{31,32}$

Off-line analysis. Neuronal recordings were exported offline as text files to a PowerLab system (ADI instruments; Phymep, Paris, France) and analysed using the Spike 2 software suite (Version 5; Cambridge Electronic Device, Cambridge, UK). Spikes were discriminated from noise and the mean firing rate, mean interspike interval (ISI) and coefficient of variation were calculated for each neuron (see Supplementary Material, and Figure S1A, D and G). Discharge patterns were classified as regular, irregular or bursting and the spike trains with bursting activity were detected for each neuron ${ }^{43}$ (see Supplementary Material). The mean bursting index $(S)$, burst frequency, duration, intraburst frequency and interval interburst were calculated for each neuron. ${ }^{34}$ Analysis of oscillatory activity was performed by frequency band using a Matlab program ${ }^{44}$ ( $\delta: 1-4 \mathrm{~Hz} ; \theta: 4-8 \mathrm{~Hz} ; \alpha: 8-12 \mathrm{~Hz} ; \beta$ low: $12-20 \mathrm{~Hz} ; \beta$ high: 20-35 Hz; $\gamma:>35 \mathrm{~Hz}$ ) (see Supplementary Material).

Imaging. The location of each recorded neuron within the functional subdivisions, that is, motor, associative and limbic, of the STN was determined by using a threedimensional deformable histological atlas adjusted to the individual brain geometry of each patient ${ }^{45,46}$ (see Supplementary Material).

STN stimulation in OCD patients. A 3-month STN stimulation period was tested in the 12 OCD patients. ${ }^{24} \mathrm{At}$ the end of the on-stimulation period, the Yale-Brown Obsessive-Compulsive Scale (Y-BOCS) score was decreased by $22 \%$ (see Supplementary Material).

Statistical analysis. Results for continuous variables are reported as mean \pm s.d. To compare neuronal activity between OCD and PD cells, we used mixed models (analysis of variance with random effect) with a random effect for patients and two fixed effects for the group (OCD vs PD) as the between-subject factor and neuronal recording localisation (sensorimotor, associative, limbic) as the withinSTN factor, and the interaction between these two fixed factors. When significant effects were found, pairs of means were compared using a Tukey-Kramer correction. For categorical data, generalised linear models with a logistic link function were used with similar effects as for the linear mixed model used for continuous data.

As changes in STN neuronal activity have been reported, we examined the differences in STN neuronal activity between OCD patients with ( $n=4$ subjects, 48 cells) and without ( $n=4$ subjects, 50 cells) neuroleptic treatment, ${ }^{47}$ and between left and right sides, ${ }^{38}$ using the Student' $t$-test for continuous variables and the Fisher's exact test for categorical variables. The relationship between the severity of 
obsessions and compulsions (Y-BOCS global and obsession and compulsion subscores), the improvement in OCD symptoms induced by STN stimulation and the STN neuronal activity characteristics were also evaluated using the nonparametric Spearman's correlation test. For these purposes, the mean discharge frequency, ISI, coefficient of variation, $S$ index, burst frequency and duration, intraburst frequency and interval interburst, the proportion of STN neurons displaying oscillatory activities, power and peak in each band frequency were calculated for each subject. The postoperative percentage improvement in OCD symptoms was calculated for each patient, as follows: (score before the on-stimulation periodscore at the end of the 3-month STN stimulation period) $\times 100$ /score before the on-stimulation period) (see Supplementary Material).

Statistical analyses were performed with the SAS 9.2 software (SAS Institute, Cary, NC, USA). The level of significance for all statistical tests was fixed at $P<0.05$. No Bonferroni correction was applied.

\section{Results}

In all, 138 cells were isolated and recorded from the STN of the 12 OCD patients and 173 cells from the STN of the 12 PD patients. The average recording duration was $59.6 \pm 39.4 \mathrm{~s}$ and the average number of spikes $1417 \pm 1191$.

Discharge frequency and pattern. The mean STN firing rate in OCD patients (STN-OCD) was significantly lower, with a higher mean ISI, compared with STN neurons of PD patients (STN-PD; Table 1). The distribution of the three types of discharge pattern in STN neurons did not differ between OCD and PD patients $(P=0.14)$, with a predominant burst-like firing pattern (Table 1). The mean bursting index, burst duration and interval interburst were significantly higher and the mean burst frequency and intraburst frequency significantly lower in STN-OCD neurons compared with STN-PD neurons (Table 1).

Oscillatory activity. Over the entire bandwidth analysed, the proportion of neurons displaying oscillatory activity was lower in STN-OCD compared with STN-PD (46 vs $68 \%$; Figure 1). In both groups, about half of the oscillatory neurons showed peaks in more than one frequency band (Figure 1). The distribution of oscillatory activity was similar in the two groups of patients, but for the presence of more $\theta$ activity in STN-OCD neurons and in the $\beta$-low band in STNPD neurons (Figure $1 \mathrm{~A} ; P<0.02$ ). The mean frequency in the $\beta$-low band was significantly lower in STN-OCD compared with STN-PD neurons (Table 1).

Influence of the neuroleptic treatment. No significant difference in neuronal activity was found between STN neurons ( $n=48$ cells) recorded in OCD patients undergoing neuroleptic treatment compared with those without $(n=50$ cells) (see Supplementary Material).

Localisation of STN neuronal activity in OCD and PD patients. A total of 81 right and 57 left STN neurons and 123
Table 1 Discharge frequency, pattern and oscillatory activity of subthalamic neurons in 12 OCD and 12 PD patients

\begin{tabular}{|c|c|c|}
\hline & $\begin{array}{l}\text { OCD patients } \\
(\mathrm{n}=138 \text { cells })\end{array}$ & $\begin{array}{c}P D \text { patients } \\
(\mathrm{n}=173 \text { cells })\end{array}$ \\
\hline Discharge frequency $(\mathrm{Hz})$ & $22.4 \pm 13.7^{\star}$ & $31.6 \pm 13.5$ \\
\hline Mean ISI (ms) & $71.8 \pm 63.5^{\star}$ & $40.1 \pm 26.3$ \\
\hline Coefficient of variation & $1.3 \pm 0.4$ & $1.2 \pm 0.3$ \\
\hline \multicolumn{3}{|c|}{ Pattern of discharge: proportion of (\%) } \\
\hline Regular & $13 \%$ & $8 \%$ \\
\hline Irregular & $18 \%$ & $24 \%$ \\
\hline Burst-type & $69 \%$ & $67 \%$ \\
\hline Burst $(S)$ index & $9.8 \pm 4.0^{*}$ & $8.3 \pm 3.1$ \\
\hline Burst frequency $(\mathrm{Hz})$ & $0.33 \pm 0.26$ & $0.41 \pm 0.28$ \\
\hline Burst duration (ms) & $823.5 \pm 665.0^{*}$ & $340.3 \pm 246.1$ \\
\hline Intraburst frequency $(\mathrm{Hz})$ & $53.7 \pm 52.6^{*}$ & $74.4 \pm 34.7$ \\
\hline Interburst interval (s) & $5.2 \pm 7.0^{*}$ & $2.9 \pm 2.6$ \\
\hline \multicolumn{3}{|l|}{ Oscillatory activity } \\
\hline \multicolumn{3}{|l|}{$\delta$ band $(1-4 \mathrm{~Hz})$} \\
\hline Peak frequency $(\mathrm{Hz})$ & $3.3 \pm 0.5$ & $3.1 \pm 0.6$ \\
\hline Peak power & $1.52 \pm 1.44$ & $1.10 \pm 1.23$ \\
\hline \multicolumn{3}{|l|}{$\theta$ band $(4-8 \mathrm{~Hz})$} \\
\hline Peak frequency $(\mathrm{Hz})$ & $5.5 \pm 1.5$ & $5.7 \pm 1.2$ \\
\hline \multicolumn{3}{|l|}{$\alpha$ band $(8-12 \mathrm{~Hz})$} \\
\hline Peak frequency $(\mathrm{Hz})$ & $9.9 \pm 1.5$ & $10.2 \pm 1.2$ \\
\hline \multicolumn{3}{|l|}{$\beta$ low $(12-20 \mathrm{~Hz})$} \\
\hline Peak frequency $(\mathrm{Hz})$ & $14.4 \pm 2.8^{*}$ & $15.8 \pm 2.5$ \\
\hline Peak power & $1.41 \pm 2.57$ & $1.59 \pm 3.04$ \\
\hline \multicolumn{3}{|l|}{$\beta$ high $(20-35 \mathrm{~Hz})$} \\
\hline Peak frequency $(\mathrm{Hz})$ & $24.5 \pm 3.3$ & $23.2 \pm 2.32$ \\
\hline \multicolumn{3}{|l|}{$\gamma$ band $(>35 \mathrm{~Hz})$} \\
\hline Peak frequency $(\mathrm{Hz})$ & $52.3 \pm 14.1$ & $56.3 \pm 16.7$ \\
\hline Peak power & $0.35 \pm 0.27$ & $0.48 \pm 0.25$ \\
\hline
\end{tabular}

Abbreviations: ISI, interspike interval; OCD, obsessive-compulsive disorder; PD, Parkinson's disease.

Results are expressed as mean \pm s.d.

${ }^{\star} P<0.05$ when compared with PD patients.

right and 50 left STN neurons were recorded in OCD and PD patients, respectively.

STN-OCD neurons were located more anteriorly than STNPD neurons, with no difference in mean laterality or depth (Table S2 and Supplementary Material). The majority of recorded neurons were located in the associative STN in both groups (Figure 2a).

Neuronal activity as a function of laterality and position within the STN. No significant differences in neuronal activity were found between right and left STN neurons in OCD patients (not shown). However, the mean bursting index, number of spikes per burst and burst duration were significantly lower in the second ( $n=36$ cells) vs the first ( $n=102$ cells) STN operated ( $P<0.04$, not shown). In PD patients, compared with the first-side STN neurons (right STN, $n=123$ cells), second-side STN neurons (left STN, $n=50$ cells) exhibited less burst-type and more regular patterns (burst-type: 72 vs $54 \%$; regular: 5 vs $14 \%, P<0.04$ ) and lower mean power in $\beta$ band oscillation $(P<0.02$, not shown).

The mean discharge frequency of STN-OCD neurons was significantly lower compared with STN-PD neurons in all subdivisions of the STN (Figure 2b; $P<0.05$ ), with no 

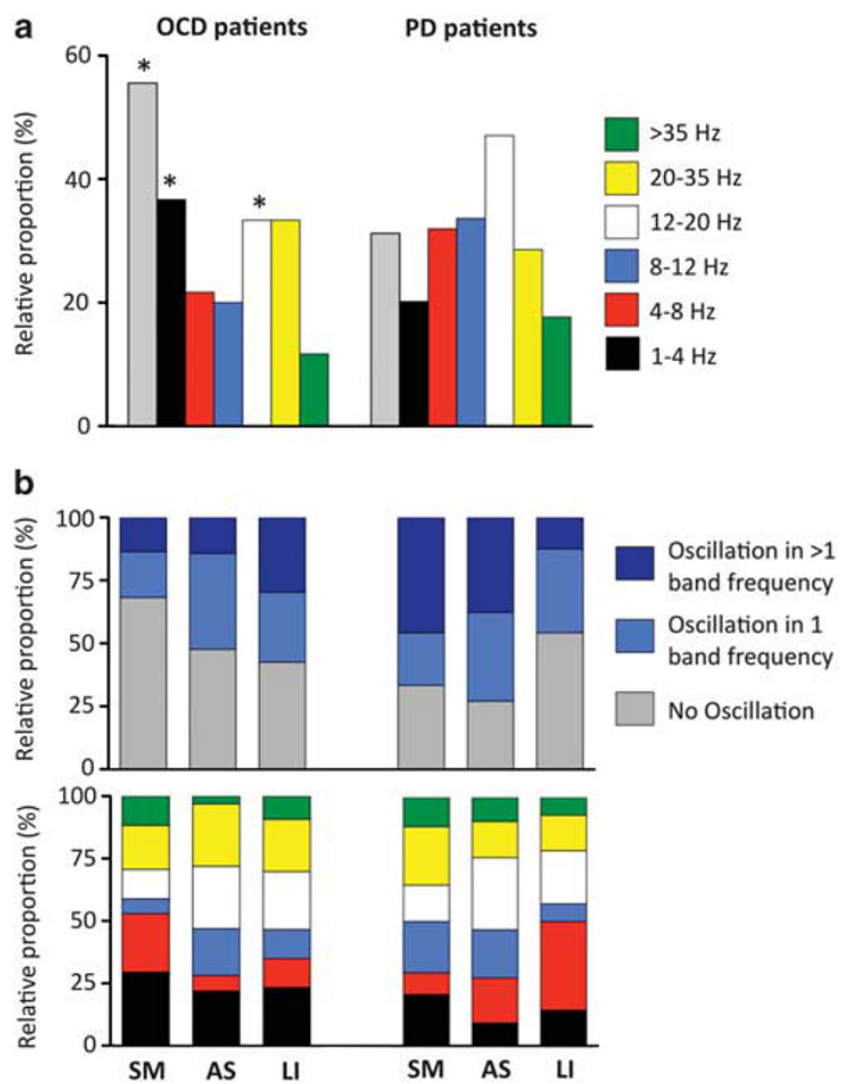

Figure 1 Distribution of oscillatory activity of subthalamic neurons recorded in obsessive-compulsive disorder (OCD) and Parkinson's disease (PD) patients. (a) Relative proportion of the 138 and 173 subthalamic nucleus (STN) neurons showing oscillatory activity in OCD and PD patients. Asterisks indicate significant differences $(P<0.05)$ between neurons of OCD and PD patients. (b) Subthalamic oscillatory activity as a function of subthalamic subdivisions in OCD and PD patients. Top histogram: relative proportion of neurons recorded in the sensorimotor (SM), associative (AS) and limbic (LI) subdivisions and showing none, one or more than one period of significant oscillatory activity. Bottom histogram: relative proportion of neurons recorded in the SM, AS and LI subdivisions and showing significant oscillatory activity in the $\theta, \alpha, \beta$-low, $\beta$-high and $\gamma$ band frequencies.

interaction between the subjects (OCD vs $P D$ ) and the neuronal recording locations (motor vs associative vs limbic) (Figure 2b; $P=0.098$ ). A significant interaction between subjects and localisation was found for the mean ISI (interaction: $P<0.03$ ). The mean ISI of the STN-OCD neurons located in the motor part was significantly higher compared with the mean ISI of the STN-OCD neurons located in the associative and limbic parts in OCD patients and with all subdivisions for STN-PD neurons ( $P<0.005$, not shown).

No significant interaction between subjects and location was found either for the pattern of discharge or for the bursting index (not shown). However, the mean bursting index of STN-OCD neurons was significantly higher in the motor and associative parts compared with STN-PD neurons recorded in the same STN territories (Figure 2c; $P<0.008$ and $P<0.005$ for the motor and associative parts, respectively). No significant interaction between subjects and location was found for the burst characteristics (burst frequency, duration of burst, intraburst frequency-not shown). However, the mean burst duration of STN-OCD neurons was significantly greater (not shown, $P<0.03$ ) and the mean intraburst frequency significantly lower in the motor part compared with STN-PD neurons recorded in the same STN territory (Figure 2d; $P<0.01$ ). A significant interaction between subjects and location was found for the interburst interval (interaction: $P<0.007$ ), which was higher in the motor part of the STN compared with the other subdivisions in OCD patients (not shown).

Over the whole frequency range, STN-OCD neurons showed more oscillation in the limbic part, whereas STN-PD neurons showed more oscillation in the motor part (Figure $1 \mathrm{~b}$; $P<0.04)$. The frequency analysis showed more oscillation for STN-PN neurons in the $\delta$ and $\alpha$ bands in the motor compared with either the associative or limbic parts of the STN (interaction: $P=0.03$; Figure $1 b$ ). STN-OCD neurons showed more oscillation in the $\alpha$ band in the limbic compared with other STN subdivisions (interaction: $P<0.001$; Figure $1 b$ ). No significant interaction between subjects and location was found for the presence of $\beta$-low, $\beta$-high or $\gamma$ oscillatory activity (Figure 1b).

Subthalamic neuronal activity as a function of obsessions and compulsions. No significant relationship was found between the preoperative severity of OCD symptoms and mean discharge frequency, bursting index and burst frequency of STN-OCD neurons (Table 2). Obsessions and compulsions severity were significantly correlated with burst duration and mean intraburst frequency and interburst interval (Table 2).

No significant relationship was found between OCD severity (Y-BOCS, obsession and compulsion subscores) and the mean proportion, peak frequency and power in the $\theta$, $\beta$-low, $\beta$-high and $\gamma$ band frequencies. The Y-BOCS global and obsession subscores were correlated with the mean peak frequency in the $\delta$ band. OCD severity was also significantly correlated with mean power in the $\delta$ frequency band and with the mean proportion of STN neurons with $\alpha$ oscillations and the mean $\alpha$ band peak frequency.

In summary, the more severe the obsessions, the lower the burst duration and interburst interval, and the higher the mean discharge and intraburst frequencies, peak and power in the $\delta$ band frequency. The more severe the compulsions, the higher the intraburst frequency and the proportion of STN neurons with $\alpha$ oscillations with lower peak frequency.

STN neuronal activity as a function of the STN stimulation efficacy. The improvement in Y-BOCS global and obsession subscores with STN stimulation was significantly correlated with the mean discharge frequency ( $r=0.86, P<0.01$; Figure $3 a)$, burst frequency $(r=0.69$, $P<0.04$; Figure $3 \mathrm{~b})$, intraburst frequency $(r=0.76, P<0.02$; Figure 3c) and the mean interburst interval $(r=-0.96$, $P<0.004$; Figure $3 d$ ) of STN neurons. The improvement in compulsion subscores with STN stimulation was significantly correlated with the mean discharge frequency $(r=0.78$, $P<0.02$; Figure 3a) and the mean interbust interval ( $r=-0.81, P<0.02$ ). No significant correlation was found between the improvement in OCD symptoms (Y-BOCS global, obsession and compulsion subscores) and the 

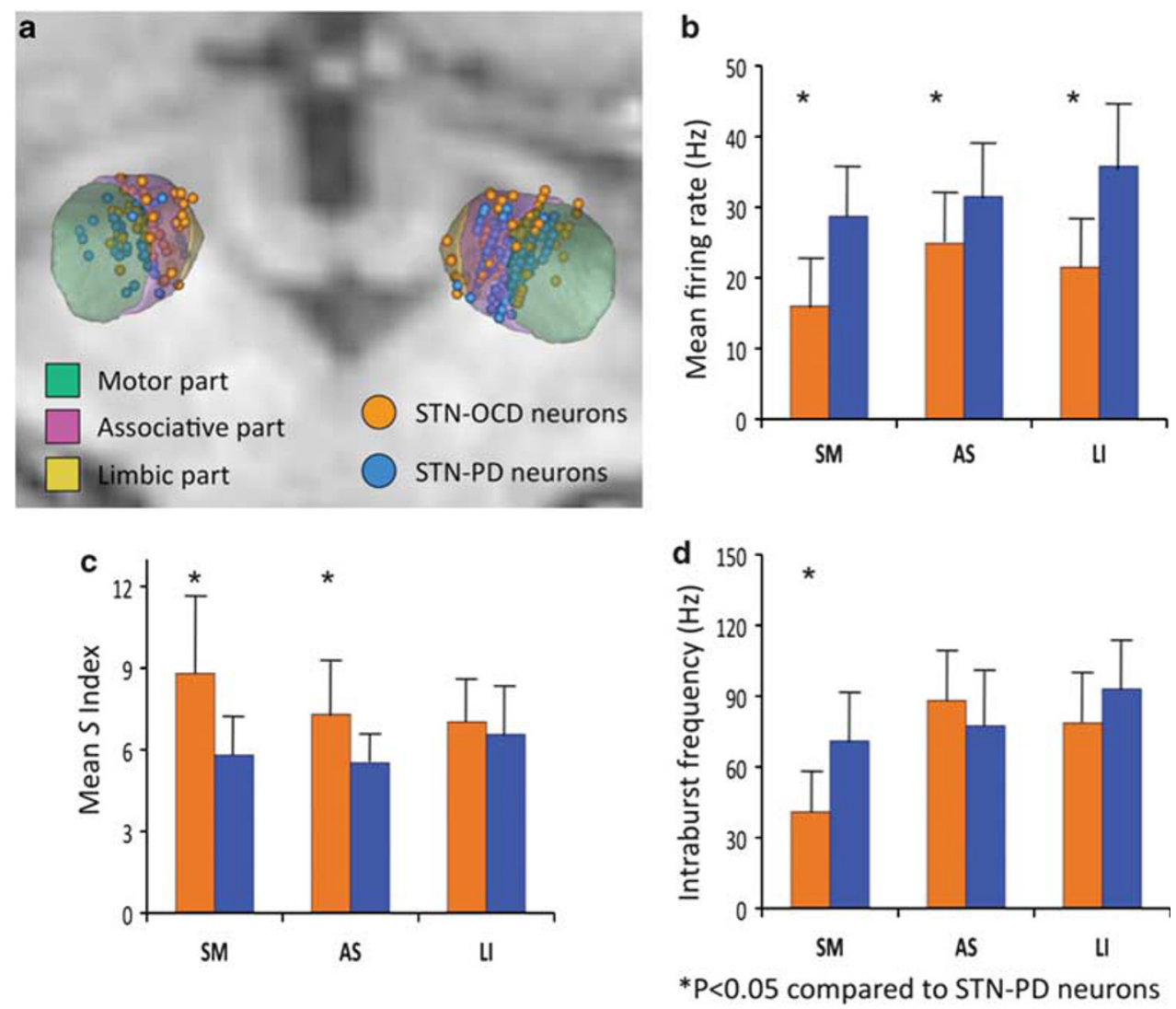

Figure 2 Subthalamic neuronal activity as a function of subthalamic subdivisions in obsessive-compulsive disorder (OCD) and Parkinson's disease (PD) patients. (a) Localisation by means of the three-dimensional (3D) digitised distortable basal ganglia atlas of all the neurons recorded in OCD and PD patients. The motor part is represented in green, the associative part in pink and the limbic part in yellow in a 3D posterior view of both sides. Each sphere represents an individual neuron (orange for subthalamic nucleus (STN)-OCD neurons and blue for STN-PD neurons). (b-d) Mean firing rate, burst index and intraburst frequency plotted against the three subthalamic subdivisions (sensorimotor, SM; associative, AS; limbic, LI) for STN neurons recorded in OCD (orange bars) and PD (blue bars) patients. Asterisks indicate significant differences $(P<0.05)$ between a given subdivision in OCD patients and the same subdivision in PD patients.

presence and characteristics (peak frequency and power) of STN oscillatory activities (not shown).

\section{Discussion}

This study reports for the first time the relationship between spontaneous subthalamic neuronal activity and symptom severity in OCD patients and their response to STN stimulation. We found that the mean firing rate of subthalamic neurons was significantly lower in OCD patients than in PD patients, with a predominantly burst-type activity, less frequent but longer bursts, and a predominant oscillatory activity in the $\delta$ band (Table 1 and Figures $1-3$ ). In patients with the most severe OCD, STN neurons exhibited bursts with higher intraburst frequency and more oscillations in the lowfrequency bands. In OCD patients with best postoperative clinical outcome with STN stimulation, STN neurons displayed higher mean discharge, burst and intraburst frequencies, but lower mean interburst interval. Neuronal activity differences observed between OCD and PD patients could result from the fact that neurons recorded in both groups were not similarly localised within the STN (Figure 2 and Supplementary Table S2). The fact that, to our knowledge, no data in the literature have shown that STN neurons are morphologically and physiologically different in different subregions of the STN, ${ }^{48}$ except for the presence of more passive movement-responsive neurons in the dorsolateral part of the STN (motor subregion), ${ }^{30,32}$ does not favour this hypothesis, however.

The mean firing rate of STN-OCD neurons was close to that reported in normal monkeys, ${ }^{49}$ essential tremor, ${ }^{34}$ dystonic ${ }^{50}$ and OCD patients. ${ }^{38}$ No significant relationship was found between firing rate and OCD severity. In our PD patients, the higher mean firing rate of STN neurons was similar to that reported previously, ${ }^{31,32,34}$ and thought to result from the disinhibition of the subthalamic activity secondary to the degeneration of nigral dopaminergic neurons. ${ }^{30,51}$ These data suggest that in OCD patients symptoms are not related to an increase or decrease in the STN neuronal discharge.

Conversely, the firing patterns were similarly distributed between OCD and PD patients, with a predominant burst-type activity (Table 1). In PD patients, the increase in burst-type activity is thought to result from the degeneration of nigral dopaminergic neurons ${ }^{30,52,53}$ and resolves with dopaminergic treatment. ${ }^{54}$ In OCD patients, the increase in the burst-type activity, also reported previously, ${ }^{38}$ could be related to the 
Table 2 Relationship between severity of obsessions and compulsions and subthalamic neuronal activity in OCD patients

\begin{tabular}{|c|c|c|c|}
\hline & Y-BOCS & Obsessions & Compulsions \\
\hline Mean discharge frequency & 0.46 & 0.54 & 0.31 \\
\hline $\begin{array}{l}\text { Burst discharges } \\
\text { Mean burst }(S) \text { index } \\
\text { Mean burst frequency } \\
\text { Mean burst duration } \\
\text { Mean intraburst frequency } \\
\text { Mean interburst interval }\end{array}$ & $\begin{array}{r}-0.32 \\
0.02 \\
-0.46 \\
\mathbf{0 . 6 8}^{\star} \\
-0.55\end{array}$ & $\begin{array}{r}-0.40 \\
0.14 \\
-0.60^{\star} \\
\mathbf{0 . 7 8 ^ { \star }} \\
-\mathbf{0 . 6 5 ^ { \star }}\end{array}$ & $\begin{array}{r}-0.32 \\
-0.03 \\
-0.40 \\
\mathbf{0 . 6 0 ^ { \star }} \\
-\mathbf{0 . 5 8 ^ { \star }}\end{array}$ \\
\hline $\begin{array}{l}\delta \text { band }(1-4 \mathrm{~Hz}) \\
\text { Mean proportion of neurons } \\
\text { Mean peak frequency } \\
\text { Mean power peak frequency }\end{array}$ & $\begin{array}{l}0.11 \\
0.79^{\star} \\
0.38\end{array}$ & $\begin{array}{c}-0.13 \\
\mathbf{0 . 8 1 ^ { * }} \\
\mathbf{0 . 6 1 ^ { * }}\end{array}$ & $\begin{array}{r}0.37 \\
-0.08 \\
-0.02\end{array}$ \\
\hline $\begin{array}{l}\theta \text { band }(4-8 \mathrm{~Hz}) \\
\text { Mean proportion of neurons } \\
\text { Mean peak frequency } \\
\text { Mean power peak frequency }\end{array}$ & $\begin{array}{r}-0.48 \\
-0.07 \\
0.17\end{array}$ & $\begin{array}{r}-0.50 \\
0.01 \\
0.10\end{array}$ & $\begin{array}{r}-0.05 \\
-0.11 \\
0.38\end{array}$ \\
\hline $\begin{array}{l}\alpha \text { band }(8-12 \mathrm{~Hz}) \\
\text { Mean proportion of neurons } \\
\text { Mean peak frequency } \\
\text { Mean power peak frequency }\end{array}$ & $\begin{array}{l}-0.45 \\
-0.12 \\
-0.26\end{array}$ & $\begin{array}{r}-0.45 \\
0.06 \\
0.02\end{array}$ & $\begin{array}{r}0.73^{\star} \\
-0.62^{\star} \\
-0.85^{\star}\end{array}$ \\
\hline $\begin{array}{l}\beta \text {-low band }(12-20 \mathrm{~Hz}) \\
\text { Mean proportion of neurons } \\
\text { Mean peak frequency } \\
\text { Mean power peak frequency }\end{array}$ & $\begin{array}{r}-0.56 \\
0.02 \\
-0.26\end{array}$ & $\begin{array}{r}-0.04 \\
-0.33 \\
0.34\end{array}$ & $\begin{array}{r}-0.02 \\
0.01 \\
-0.07\end{array}$ \\
\hline $\begin{array}{l}\beta \text {-high band }(20-35 \mathrm{~Hz}) \\
\text { Mean proportion of neurons } \\
\text { Mean peak frequency } \\
\text { Mean power peak frequency }\end{array}$ & $\begin{array}{r}-0.50 \\
-0.04 \\
0.40\end{array}$ & $\begin{array}{r}-0.30 \\
-0.10 \\
0.27\end{array}$ & $\begin{array}{r}0.12 \\
-0.27 \\
0.20\end{array}$ \\
\hline $\begin{array}{l}\gamma \text { band }(>35 \mathrm{~Hz}) \\
\text { Mean proportion of neurons } \\
\text { Mean peak frequency } \\
\text { Mean power peak frequency }\end{array}$ & $\begin{array}{l}-0.22 \\
-0.32 \\
-0.32\end{array}$ & $\begin{array}{r}0.03 \\
0.11 \\
-0.34\end{array}$ & $\begin{array}{l}-0.49 \\
-0.01 \\
-0.40\end{array}$ \\
\hline
\end{tabular}

Abbreviations: OCD, obsessive-compulsive disorder; Y-BOCS, Yale-Brown Obsessive-Compulsive Scale.

Values are correlation coefficients (non-parametric Spearman's regression).

Entries shown in bold ${ }^{\star} P<0.05$ after univariate analysis.

intake of neuroleptic treatment resulting in a dopaminergic receptors blockage, as previously reported in animal studies. ${ }^{47}$ However, the fact that the proportion of bursting STN neurons was similar in the four OCD patients who received neuroleptic treatment in the days before surgery compared with the four OCD patients without neuroleptic treatment (64 vs $74 \%$ ) fails to support this hypothesis, as discussed previously. ${ }^{38}$ Compared with STN-PD neurons, STN-OCD neurons have a higher bursting index with longer but less frequent bursts (Table 1), and OCD severity was significantly related to some burst characteristics (Table 2). Moreover, OCD improvements with STN stimulation were dependent on a number of burst characteristics, with a higher response for patients with lower interburst interval, but higher intraburst frequency (Figure 3). Some burst characteristics decreased in neurons recorded in the second STN side operated, whichever the side. This could reflect a lesioning effect provoked by the implantation of the first lead resulting in a microsubthalamotomy, ${ }^{55}$ as previously reported with unilateral STN lesion $^{56}$ or stimulation, ${ }^{57}$ and not a pathological marker per se as suggested previously. ${ }^{38}$ With respect to the functional connectivity of the basal ganglia network, the increase in bursting activity in the STN observed in our OCD patients could be related to a decrease in the inhibitory phasic input from the GPe, which has been proposed to scale its activity depending on the basal ganglia cortical input via the striatum. ${ }^{58}$ It is known that the functional alterations in basal ganglia circuitry observed in OCD patients occur mainly along the ventral frontostriatal axis, with heightened activity in the orbitofrontal cortex and caudate nuclei. ${ }^{8,59}$ Moreover, an increase in striatal neuronal activity with more irregular pattern has been observed in OCD patients experiencing obsessions. ${ }^{29}$ Given the neuroanatomical connectivity of the basal ganglia, one might expect that an increase in striatal activity would result in an increase in inhibitory phasic input from the striatum to the GPe provoking a decrease of inhibitory GPe input to the STN, leading in turn to an increase in bursting activity. ${ }^{42,51,60}$ Cortical activity may also influence STN neuronal activity through the so-called hyperdirect pathway. ${ }^{61}$ Abnormal ventral STN and striatal neuronal activity could then result in a disruption of information processing at the level of basal ganglia output and the thalamocortical pathway in line with the abnormal activity observed at the cortical level in OCD patients, especially in the orbitofrontal and anterior cingulate cortices. ${ }^{62-65}$ Finally, the improvement in OCD symptoms by modulation of the STN neuronal activity with high-frequency 

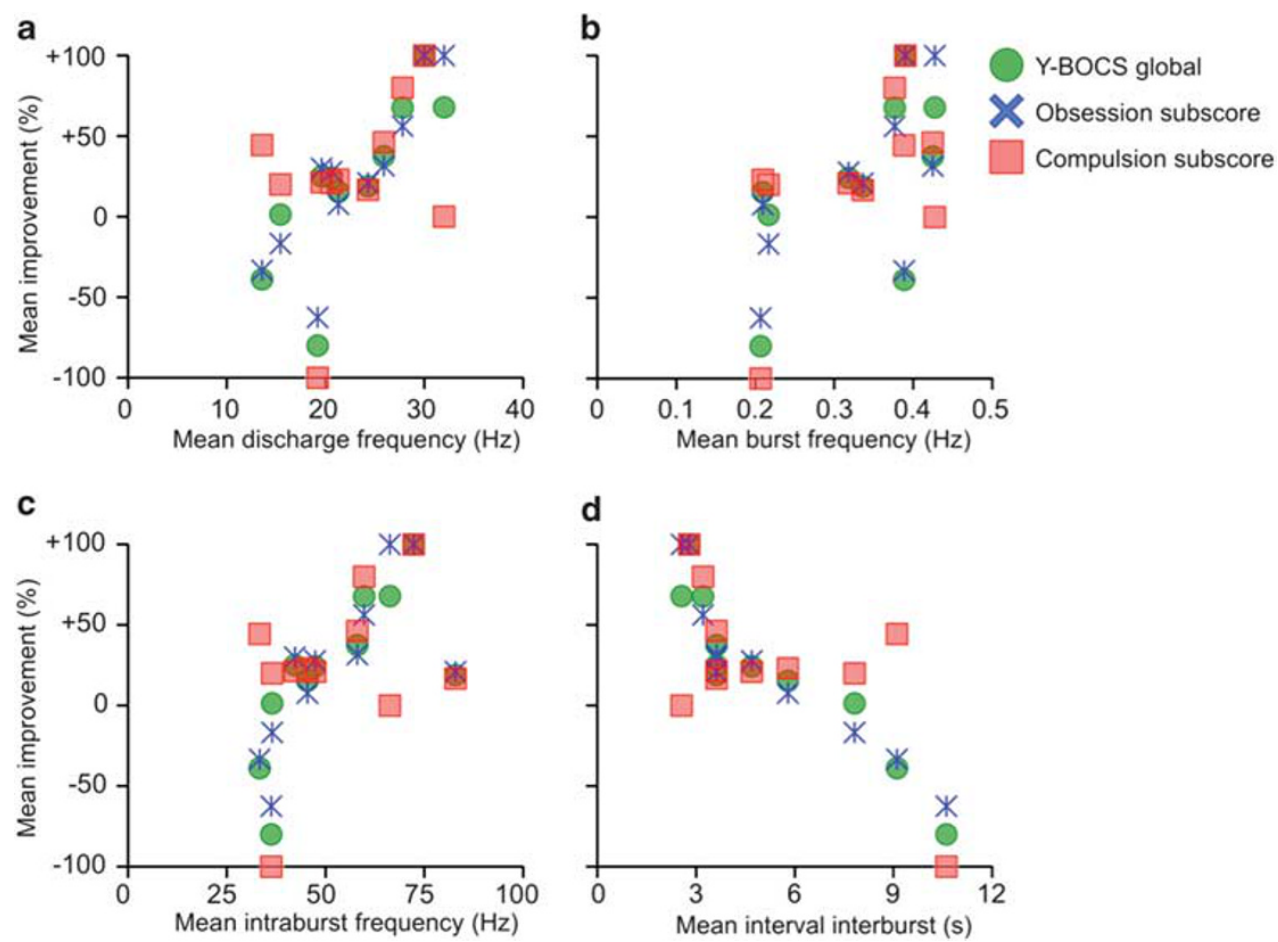

Figure 3 Improvement in obsessions and compulsions with subthalamic nucleus stimulation as a function of subthalamic neuronal activity in obsessive-compulsive disorder patients. The graphs represent the relationship between the improvement in the Yale-Brown Obsessive-Compulsive Scale (Y-BOCS) global (green circles), obsession (blue crosses) and compulsion (red squares) subscores and the mean (a) discharge frequency, (b) burst frequency, (c) intraburst frequency and (d) interburst interval.

stimulation may be related to changes in these cortical regions, as recently reported in the same group of patients. ${ }^{66}$

In our OCD patients, about half of the STN neurons displayed oscillatory activity (Figure 1). Conversely, in other non-parkinsonian patients, such as those suffering from essential tremor or dystonia, only 18 and $6.5 \%$ of STN neurons show oscillatory activity in the $3-30 \mathrm{~Hz}$ band frequency, respectively. ${ }^{34,50}$ This observation suggests that oscillatory activity is augmented in the STN of OCD patients. A simple explanation could be that the high proportion of oscillations observed in STN-OCD neurons is related to neuroleptic treatment; however, the fact that oscillations tended to be less frequent in STN neurons of OCD patients undergoing neuroleptic treatment $(42 \%)$ compared with STN neurons of OCD patients without (74\%) fails to support this hypothesis. In PD patients, STN oscillation predominated in the STN motor part, as reported previously. ${ }^{34,67}$ In the $\delta$ and $\alpha$ band frequencies, oscillations appear to be related to tremor, ${ }^{30,67}$ and in the $\beta$ band to movement inhibition and akinesia ${ }^{33,35,68,69}$ and predictive of STN stimulation outcome. $^{36,37}$ In OCD patients, $\delta$ and $\alpha$ frequency band oscillation, which predominated in the STN associative and limbic parts, was significantly related to OCD symptom severity (Table 2). Our results are in line with reports obtained with EEG techniques in such patients who show an increase in low-frequency $(\delta, \theta$ and $\alpha)$ oscillation, in resting state activity, at both cortical (in frontal and frontotemporal regions) ${ }^{70-72}$ and subcortical (in the thalamus and the striatum) ${ }^{2}$ levels, and related to symptom severity. ${ }^{70,71,73}$ Lastly, whereas $\beta$ band
STN oscillatory activity has been identified as a marker of akinesia in PD patients, ${ }^{33,69}$ about $35 \%$ of STN neurons exhibited $\beta$ band oscillations in OCD patients (Figure 1). This result is in line with the report of a relationship between the severity of symptoms and $\beta$ band power in frontal cortical regions in untreated OCD patients. ${ }^{71} \mathrm{An}$ increase in the $\beta$ power frequency has also been identified as one of the bioelectrical markers in various anxious states, ${ }^{74,75}$ and the question remains as to whether oscillations in the $\beta$ band activity observed in the STN of OCD patients could be related to anxiety. Finally, the increase in low frequencies observed in the STN in our OCD patients, predominantly in the limbic portion, is consistent with changes reported at the limbic cortical level and support the hypothesis of an involvement of cortico-subcortical functional connections in this disorder. ${ }^{1}$

Significant relationships between STN neuronal activities, which resembled parkinsonian STN neuronal activity (higher firing rate, burst and intraburst frequencies, and lower interburst interval), and STN stimulation efficacy were found in our OCD patients. This could mean that the main dysfunction in OCD patients improved by STN stimulation is one of the nigrostriatal dopaminergic system. However, this hypothesis seems unlikely as these neuronal activities were not identified as being predictive of the STN stimulation efficacy in PD patients. ${ }^{36,37}$ This result would rather suggest that OCD patients with a more disturbed STN neuronal activity are better candidates for this surgical treatment. The electrophysiological effects of high-frequency STN stimulation are not fully understood; however, a decrease in neuronal 
activity in the STN with retrograde and anterograde activations of input (cortex and $\mathrm{GPe}$ ) and output (GPi and $\mathrm{SNr}$ ) structures has been reported in patients and animal models of PD. ${ }^{43,47,57,76-81}$ Finally, the therapeutic effect of highfrequency stimulation of the STN is thought to result from complex changes in the neuronal activity of the entire corticobasal ganglia circuitry, leading to a disruption of the pathological neuronal activity.

In conclusion, STN neurons in OCD patients display increased bursting activity with a high proportion of oscillatory activity, in relation to symptom severity and response to STN stimulation. In line with the accepted role of the STN in decision making and action sequencing, ${ }^{58,82}$ one might expect that dysfunction of this subcortical region could result in the setting of an inappropriate (increase or decrease) decision threshold in the context of reinforcement and decision conflicts. Consequently, an increase in this threshold could result, at least in part, in an inability to make a decision or a difficulty in terminating an action sequence, thereby resulting in obsessions and compulsions. Lastly, the fact that some STN neuronal activity characteristics are predictive of the STN stimulation-induced improvement suggests that some patients may be considered as good candidates for this treatment regarding the predominant involvement of the STN in the occurrence of their symptoms. This hypothesis will be explored in future studies.

\section{Conflict of interest}

The authors declare no conflict of interest.

Acknowledgements. We thank Pierre Pouget, $\mathrm{PhD}$, for his constructive advice in data analysis, and Michel Goillandeau for his contribution to data export and Max Westby, PhD, for critical reading of the manuscript. This study was supported by the Assistance-Publique Hôpitaux de Paris (APHP, P030422); Fondation pour la Recherche sur le Cerveau grant 2008, Agence Nationale de la Recherche grant 2006 (No. ANR-06-NEURO-006-01 BG EMO/PATH 2006-2010).

Author contributions: Dr Welter had full access to all of the data in the study and takes responsibility for the integrity of the data and the accuracy of the data analysis.

1. Velikova S, Locatelli M, Insacco C, Smeraldi E, Comi G, Leocani L. Dysfunctional brain circuitry in obsessive-compulsive disorder: source and coherence analysis of EEG rhythms. Neuroimage 2010; 49: 977-983.

2. Bolwig TG, Hansen ES, Hansen A, Merkin H, Prichep LS. Toward a better understanding of the pathophysiology of OCD SSRI responders: QEEG source localization. Acta Psychiatr Scand 2007; 115: 237-242.

3. Baxter Jr LR, Phelps ME, Mazziotta JC, Guze BH, Schwartz JM, Selin CE. Local cerebral glucose metabolic rates in obsessive-compulsive disorder. A comparison with rates in unipolar depression and in normal controls. Arch Gen Psychiatry 1987; 44: 211-218.

4. Baxter Jr LR. Neuroimaging studies of obsessive-compulsive disorder. Psychiatr Clin N Am 1992; 15: 871-884.

5. Benkelfat C, Nordahl TE, Semple WE, King AC, Murphy DL, Cohen RM. Local cerebral glucose metabolic rates in obsessive-compulsive disorder. Patients treated with clomipramine. Arch Gen Psychiatry 1990; 47: 840-848.

6. Schwartz JM, Stoessel PW, Baxter Jr LR, Martin KM, Phelps ME. Systematic changes in cerebral glucose metabolic rate after successful behavior modification treatment of obsessive-compulsive disorder. Arch Gen Psychiatry 1996; 53: 109-113.

7. Saxena S, Brody AL, Schwartz JM, Baxter LR. Neuroimaging and frontal-subcortical circuitry in obsessive-compulsive disorder. Br J Psychiatry Suppl 1998; 35: 26-37.

8. Harrison BJ, Soriano-Mas C, Pujol J, Ortiz H, Lopez-Sola M, Hernandez-Ribas R et al. Altered corticostriatal functional connectivity in obsessive-compulsive disorder. Arch Gen Psychiatry 2009; 66: 1189-1200.
9. Rotge JY, Langbour N, Guehl D, Bioulac B, Jaafari N, Allard M et al. Gray matter alterations in obsessive-compulsive disorder: an anatomic likelihood estimation metaanalysis. Neuropsychopharmacology 2010; 35: 686-691.

10. Nuttin B, Cosyns P, Demeulemeester H, Gybels J, Meyerson B. Electrical stimulation in anterior limbs of internal capsules in patients with obsessive-compulsive disorder. Lancet 1999; 354: 1526.

11. Aouizerate B, Cuny E, Martin-Guehl C, Guehl D, Amieva H, Benazzouz A et al. Deep brain stimulation of the ventral caudate nucleus in the treatment of obsessive-compulsive disorder and major depression. Case report. J Neurosurg 2004; 101: 682-686.

12. Greenberg BD, Malone DA, Friehs GM, Rezai AR, Kubu CS, Malloy PF et al. Three-year outcomes in deep brain stimulation for highly resistant obsessive-compulsive disorder. Neuropsychopharmacology 2006; 31: 2384-2393.

13. Goodman WK, Foote KD, Greenberg BD, Ricciuti N, Bauer R, Ward H et al. Deep brain stimulation for intractable obsessive-compulsive disorder: pilot study using a blinded, staggered-onset design. Biol Psychiatry 2010; 67: 535-542.

14. Aouizerate B, Cuny E, Bardinet E, Yelnik J, Martin-Guehl C, Rotge JY et al. Distinct striatal targets in treating obsessive-compulsive disorder and major depression. $J$ Neurosurg 2009; 111: 775-779.

15. Sturm V, Lenartz D, Koulousakis A, Treuer H, Herholz K, Klein JC et al. The nucleus accumbens: a target for deep brain stimulation in obsessive-compulsive- and anxietydisorders. J Chem Neuroanat 2003; 26: 293-299.

16. Fahn S, Elton R, Members of UPDRS Development Committee. Unified Parkinson's disease rating scale. In: Fahn S, Marsden C, Calne D, Goldstein M (eds). Recent Developments in Parkinson's Disease, Vol. 2 Macmillan: New York, 1987, pp 153-163.

17. Mallet L, Mesnage V, Houeto JL, Pelissolo A, Yelnik J, Behar C et al. Compulsions, Parkinson's disease, and stimulation. Lancet 2002; 360: 1302-1304.

18. Fontaine D, Mattei V, Borg M, von Langsdorff D, Magnie MN, Chanalet $S$ et al. Effect of subthalamic nucleus stimulation on obsessive-compulsive disorder in a patient with Parkinson disease. Case report. J Neurosurg 2004; 100: 1084-1086.

19. Grabli D, McCairn K, Hirsch EC, Agid Y, Feger J, Francois C et al. Behavioural disorders induced by external globus pallidus dysfunction in primates: I. Behavioural study. Brain 2004; 127: 2039-2054.

20. Karachi C, Yelnik J, Tande D, Tremblay L, Hirsch EC, Francois C. The pallidosubthalamic projection: an anatomical substrate for nonmotor functions of the subthalamic nucleus in primates. Mov Disord 2005; 20: 172-180.

21. Mallet L, Schupbach M, N'Diaye K, Remy P, Bardinet E, Czernecki V et al. Stimulation of subterritories of the subthalamic nucleus reveals its role in the integration of the emotional and motor aspects of behavior. Proc Natl Acad Sci USA 2007; 104: 10661-10666.

22. Aron AR, Poldrack RA. Cortical and subcortical contributions to Stop signal response inhibition: role of the subthalamic nucleus. J Neurosci 2006; 26: 2424-2433.

23. Eagle DM, Baunez C, Hutcheson DM, Lehmann O, Shah AP, Robbins TW. Stop-signal reaction-time task performance: role of prefrontal cortex and subthalamic nucleus. Cereb Cortex 2008; 18: 178-188.

24. Mallet L, Polosan M, Jaafari N, Baup N, Welter ML, Fontaine D et al. Subthalamic nucleus stimulation in severe obsessive-compulsive disorder. N Engl J Med 2008; 359: 2121-2134.

25. Baup N, Grabli D, Karachi C, Mounayar S, Francois C, Yelnik J et al. High-frequency stimulation of the anterior subthalamic nucleus reduces stereotyped behaviors in primates. $J$ Neurosci 2008; 28: 8785-8788.

26. Winter C, Mundt A, Jalali R, Joel D, Harnack D, Morgenstern R et al. High frequency stimulation and temporary inactivation of the subthalamic nucleus reduce quinpiroleinduced compulsive checking behavior in rats. Exp Neurol 2008; 210: 217-228.

27. Klavir O, Flash S, Winter C, Joel D. High frequency stimulation and pharmacological inactivation of the subthalamic nucleus reduces 'compulsive' lever-pressing in rats. Exp Neurol 2009; 215: 101-109.

28. Rouaud T, Lardeux S, Panayotis N, Paleressompoulle D, Cador M, Baunez C. Reducing the desire for cocaine with subthalamic nucleus deep brain stimulation. Proc Natl Acad Sci USA 2010; 107: 1196-1200.

29. Guehl D, Benazzouz A, Aouizerate B, Cuny E, Rotge JY, Rougier A et al. Neuronal correlates of obsessions in the caudate nucleus. Biol Psychiatry 2008; 63: 557-562.

30. Bergman H, Wichmann T, Karmon B, DeLong MR. The primate subthalamic nucleus. II. Neuronal activity in the MPTP model of parkinsonism. J Neurophysiol 1994; 72: 507-520.

31. Hutchison WD, Allan RJ, Opitz H, Levy R, Dostrovsky JO, Lang AE et al. Neurophysiological identification of the subthalamic nucleus in surgery for Parkinson's disease. Ann Neurol 1998; 44: 622-628.

32. Rodriguez-Oroz MC, Rodriguez M, Guridi J, Mewes K, Chockkman V, Vitek J et al. The subthalamic nucleus in Parkinson's disease: somatotopic organization and physiological characteristics. Brain 2001; 124: 1777-1790.

33. Brown P. Bad oscillations in Parkinson's disease. J Neural Transm Supp/ 2006; 70: 27-30.

34. Steigerwald F, Potter M, Herzog J, Pinsker M, Kopper F, Mehdorn H et al. Neuronal activity of the human subthalamic nucleus in the parkinsonian and nonparkinsonian state. J Neurophysiol 2008; 100: 2515-2524.

35. Levy R, Ashby P, Hutchison WD, Lang AE, Lozano AM, Dostrovsky JO. Dependence of subthalamic nucleus oscillations on movement and dopamine in Parkinson's disease. Brain 2002; 125: 1196-1209.

36. Ray NJ, Jenkinson N, Wang S, Holland P, Brittain JS, Joint C et al. Local field potential beta activity in the subthalamic nucleus of patients with Parkinson's disease is associated with 
improvements in bradykinesia after dopamine and deep brain stimulation. Exp Neurol 2008; 213: 108-113

37. Zaidel A, Spivak A, Grieb B, Bergman H, Israel Z. Subthalamic span of beta oscillations predicts deep brain stimulation efficacy for patients with Parkinson's disease. Brain 2010; 133: 2007-2021.

38. Piallat B, Polosan M, Fraix V, Goetz L, David O, Fenoy A et al. Subthalamic neuronal firing in obsessive-compulsive disorder and Parkinson disease. Ann Neurol 2010.

39. Welter ML, Houeto JL, Tezenas du Montcel S, Mesnage V, Bonnet AM, Pillon B et al. Clinical predictive factors of subthalamic stimulation in Parkinson's disease. Brain 2002 125: 575-583.

40. Bejjani BP, Dormont D, Pidoux B, Yelnik J, Damier P, Arnulf I et al. Bilateral subthalamic stimulation for Parkinson's disease by using three-dimensional stereotactic magnetic resonance imaging and electrophysiological guidance. J Neurosurg 2000; 92: 615-625.

41. Karachi C, Francois C, Parain K, Bardinet E, Tande D, Hirsch E et al. Three-dimensiona cartography of functional territories in the human striatopallidal complex by using calbindin immunoreactivity. J Comp Neurol 2002; 450: 122-134.

42. Yelnik J. Functional anatomy of the basal ganglia. Mov Disord 2002; 17: S15-S21.

43. Maltete D, Jodoin N, Karachi C, Houeto JL, Navarro S, Cornu P et al. Subthalamic stimulation and neuronal activity in the substantia nigra in Parkinson's disease. $J$ Neurophysiol 2007; 97: 4017-4022.

44. Muresan RC, Jurjut OF, Moca VV, Singer W, Nikolic D. The oscillation score: an efficient method for estimating oscillation strength in neuronal activity. J Neurophysiol 2008; 99 1333-1353.

45. Yelnik J, Bardinet E, Dormont D, Malandain G, Ourselin S, Tande D et al. A threedimensional, histological and deformable atlas of the human basal ganglia. I. Atlas construction based on immunohistochemical and MRI data. Neuroimage 2007; 34: 618-638

46. Bardinet E, Bhattacharjee M, Dormont D, Pidoux B, Malandain G, Schupbach M et al. A three-dimensional histological atlas of the human basal ganglia. II. Atlas deformation strategy and evaluation in deep brain stimulation for Parkinson disease. J Neurosurg 2009; 110: 208-219.

47. Degos B, Deniau JM, Thierry AM, Glowinski J, Pezard L, Maurice N. Neuroleptic-induced catalepsy: electrophysiological mechanisms of functional recovery induced by highfrequency stimulation of the subthalamic nucleus. J Neurosci 2005; 25: 7687-7696.

48. Hamani C, Saint-Cyr JA, Fraser J, Kaplitt M, Lozano AM. The subthalamic nucleus in the context of movement disorders. Brain 2004; 127: 4-20.

49. Wichmann T, Bergman H, DeLong MR. The primate subthalamic nucleus. I. Functional properties in intact animals. J Neurophysiol 1994; 72: 494-506.

50. Schrock LE, Ostrem JL, Turner RS, Shimamoto SA, Starr PA. The subthalamic nucleus in primary dystonia: single-unit discharge characteristics. J Neurophysiol 2009; 102: $3740-3752$.

51. Alexander GE. Basal ganglia-thalamocortical circuits: their role in control of movements. $J$ Clin Neurophysiol 1994; 11: 420-431.

52. Wichmann T, Soares J. Neuronal firing before and after burst discharges in the monkey basal ganglia is predictably patterned in the normal state and altered in parkinsonism. $J$ Neurophysiol 2006; 95: 2120-2133.

53. Breit S, Bouali-Benazzouz R, Popa RC, Gasser T, Benabid AL, Benazzouz A. Effects of 6 hydroxydopamine-induced severe or partial lesion of the nigrostriatal pathway on the neuronal activity of pallido-subthalamic network in the rat. Exp Neurol 2007; 205: 36-47.

54. Levy R, Dostrovsky JO, Lang AE, Sime E, Hutchison WD, Lozano AM. Effects of apomorphine on subthalamic nucleus and globus pallidus internus neurons in patients with Parkinson's disease. J Neurophysiol 2001; 86: 249-260.

55. Maltete D, Chastan N, Derrey S, Debono B, Gerardin E, Lefaucheur R et al Microsubthalamotomy effect at day 3: screening for determinants. Mov Disord 2009; 24: 286-289.

56. Mouroux M, Hassani OK, Feger J. Electrophysiological study of the excitatory parafascicular projection to the subthalamic nucleus and evidence for ipsi- and contralateral controls. Neuroscience 1995; 67: 399-407.

57. Walker HC, Watts RL, Schrandt CJ, Huang H, Guthrie SL, Guthrie BL et al. Activation of subthalamic neurons by contralateral subthalamic deep brain stimulation in Parkinson disease. J Neurophysiol 2010; 105: 1112-1121.

58. Mink JW. The basal ganglia: focused selection and inhibition of competing motor programs Prog Neurobiol 1996; 50: 381-425.

59. Remijnse PL, Nielen MM, van Balkom AJ, Cath DC, van Oppen $\mathrm{P}$, Uylings $\mathrm{HB}$ et al. Reduced orbitofrontal-striatal activity on a reversal learning task in obsessive-compulsive disorder. Arch Gen Psychiatry 2006; 63: 1225-1236.

60. Obeso JA, Rodriguez-Oroz MC, Rodriguez M, Lanciego JL, Artieda J, Gonzalo N et al. Pathophysiology of the basal ganglia in Parkinson's disease. Trends Neurosci 2000; 23 S8-19.

61. Nambu A, Tokuno H, Takada M. Functional significance of the cortico-subthalamo-pallidal 'hyperdirect' pathway. Neurosci Res 2002; 43: 111-117.

62. Rauch SL, Jenike MA, Alpert NM, Baer L, Breiter HC, Savage CR et al. Regional cerebral blood flow measured during symptom provocation in obsessive-compulsive disorder using oxygen 15-labeled carbon dioxide and positron emission tomography. Arch Gen Psychiatry 1994; 51: 62-70.

63. Breiter HC, Rauch SL, Kwong KK, Baker JR, Weisskoff RM, Kennedy DN et al. Functional magnetic resonance imaging of symptom provocation in obsessive-compulsive disorder. Arch Gen Psychiatry 1996; 53: 595-606.

64. Adler CM, McDonough-Ryan P, Sax KW, Holland SK, Arndt S, Strakowski SM. fMRI of neuronal activation with symptom provocation in unmedicated patients with obsessivecompulsive disorder. J Psychiatr Res 2000; 34: 317-324. 64

65. Rotge JY, Guehl D, Dilharreguy B, Cuny E, Tignol J, Bioulac B et al. Provocation of obsessive-compulsive symptoms: a quantitative voxel-based meta-analysis of functional neuroimaging studies. J Psychiatry Neurosci 2008; 33: 405-412.

66. Le Jeune F, Vérin M, N'Diaye K, Drapier D, Leray E, Du Montcel ST et al. Decrease of prefrontal metabolism after subthalamic stimulation in obsessive-compulsive disorder: a positron emission tomography study. Biol Psychiatry 2010; 68: 1016-1022.

67. Levy R, Hutchison WD, Lozano AM, Dostrovsky JO. High-frequency synchronization of neuronal activity in the subthalamic nucleus of parkinsonian patients with limb tremor. $J$ Neurosci 2000; 20: 7766-7775.

68. Kuhn AA, Williams D, Kupsch A, Limousin P, Hariz M, Schneider GH et al. Event-related beta desynchronization in human subthalamic nucleus correlates with motor performance. Brain 2004; 127: 735-746

69. Weinberger M, Hutchison WD, Dostrovsky JO. Pathological subthalamic nucleus oscillations in PD: can they be the cause of bradykinesia and akinesia? Exp Neurol 2009; 219: 58-61.

70. Karadag F, Oguzhanoglu NK, Kurt T, Oguzhanoglu A, Atesci F, Ozdel O. Quantitative EEG analysis in obsessive-compulsive disorder. Int J Neurosci 2003; 113: 833-847.

71. Pogarell O, Juckel G, Mavrogiorgou P, Mulert C, Folkerts M, Hauke W et al. Symptomspecific EEG power correlations in patients with obsessive-compulsive disorder. Int $J$ Psychophysiol 2006; 62: 87-92.

72. Desarkar P, Sinha VK, Jagadheesan K, Nizamie SH. Subcortical functioning in obsessivecompulsive disorder: an exploratory EEG coherence study. World J Biol Psychiatry 2007; 8: $196-200$.

73. Sherlin L, Congedo M. Obsessive-compulsive dimension localized using low-resolution brain electromagnetic tomography (LORETA). Neurosci Lett 2005; 387: 72-74.

74. Isotani T, Tanaka H, Lehmann D, Pascual-Marqui RD, Kochi K, Saito N et al. Source localization of EEG activity during hypnotically induced anxiety and relaxation. Int $J$ Psychophysiol 2001; 41: 143-153.

75. Sachs G, Anderer P, Dantendorfer K, Saletu B. EEG mapping in patients with social phobia. Psychiatry Res 2004; 131: 237-247.

76. Welter ML, Houeto JL, Bonnet AM, Bejjani PB, Mesnage V, Dormont D et al. Effects of high-frequency stimulation on subthalamic neuronal activity in Parkinsonian patients. Arch Neurol 2004; 61: 89-96.

77. Benazzouz A, Gao DM, Ni ZG, Piallat B, Bouali-Benazzouz R, Benabid AL. Effect of highfrequency stimulation of the subthalamic nucleus on the neuronal activities of the substantia nigra pars reticulata and ventrolateral nucleus of the thalamus in the rat. Neuroscience 2000; 99: 289-295

78. Hashimoto T, Elder CM, Okun MS, Patrick SK, Vitek JL. Stimulation of the subthalamic nucleus changes the firing pattern of pallidal neurons. J Neurosci 2003; 23: 1916-1923.

79. Li S, Arbuthnott GW, Jutras MJ, Goldberg JA, Jaeger D. Resonant antidromic cortical circuit activation as a consequence of high-frequency subthalamic deep-brain stimulation. $J$ Neurophysiol 2007; 98: 3525-3537.

80. Gradinaru V, Mogri M, Thompson KR, Henderson JM, Deisseroth K. Optical deconstruction of parkinsonian neural circuitry. Science 2009; 324: 354-359.

81. Deniau JM, Degos B, Bosch C, Maurice N. Deep brain stimulation mechanisms: beyond the concept of local functional inhibition. Eur J Neurosci 2010; 32: 1080-1091.

82. Frank MJ, Samanta J, Moustafa AA, Sherman SJ. Hold your horses: impulsivity, deep brain stimulation, and medication in parkinsonism. Science 2007; 318: 1309-1312.
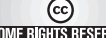

Translational Psychiatry is an open-access journal published by Nature Publishing Group. This work is licensed under the Creative Commons Attribution-NoncommercialNo Derivative Works 3.0 Unported License. To view a copy of this license, visit http://creativecommons.org/licenses/by-nc-nd/3.0/

Supplementary Information accompanies the paper on the Translational Psychiatry website (http://www.nature.com/tp) 


\section{Appendix}

Members of the French STOC Study Group were as follows: Trial Coordination: L. Mallet (Centre d'Investigation Clinique, CHU Pitié-Salpêtrière, Paris). Steering Committee: Y. Agid, B. Aouizerate, C. Arbus, T. Bougerol, P. Damier, D. Fontaine, J.L. Houeto, M.O. Krebs, J.J. Lemaire, L. Mallet, B. Millet, P. Pollak. Logistics and Monitoring: D. Hourton, S. Aprelon, C. Jourdain (Assistance Publique-Hôpitaux de Paris, Direction de la Recherche Clinique, Paris). Coordinating teams: Anatomy: E. Bardinet, J. Yelnik; Electrophysiology: P. Burbaud, M.L. Welter, A.H. Clair; Neuropsychology: C. Czernecki, M. Vérin. Data Management and Statistical Analysis: S. Tézenas du Montcel, D. Madar (Unité de Recherche Clinique, CHU Pitié-Salpêtrière, Paris). Writing Committee: L. Mallet, A. Pelissolo, S. Tezenas du Montcel, M.L. Welter, J. Yelnik. Centers (Principal Investigator: PI, Co-investigators: psychiatrist $(P)$, neurosurgeon $(N)$, neurologist (NI), electrophysiologist $(E)$, radiologist $(R)$, neuropsychologist (Np)): Coordinating Center, Paris Pitié-Salpêtrière Hospital: L. Mallet (PI, P), A. Pelissolo (PI, P), Y. Agid (NI), P. Cornu (N), S. Navarro (N), M.L. Welter (E, NI), A. Hartmann (NI), B. Pidoux (E), D. Grabli (NI), V. Czernecki (Np), D. Dormont (R), D. Galanaud (R), J. Yelnik, E. Bardinet,
C. Béhar (Np), Y. Worbe (NI), A.H. Clair (Np), B. Moutaud, $\mathrm{CIC}$ staff and nurses; Bordeaux: B. Aouizerate $(\mathrm{PI}, \mathrm{P})$, P. Burbaud (E), E. Cuny (N), D. Guehl (NI); Clermont-Ferrand: P.M. Llorca (PI, P), I Chéreau (P), J.J. Lemaire (N), F. Durif (NI), P. Derost (NI), J. Coste (E); J. Gabrillargues, M. Barget, I. de Chazeron; Grenoble: T. Bougerol (PI, P), M. Polosan (P), A.L. Benabid $(N)$, S. Chabardès $(N)$, E. Seigneuret $(N)$, P. Krack (NI), P. Pollak (NI), C. Ardouin (Np), J.F. Le Bas (R); Nantes: P. Damier (PI, NI), Y. Lajat (N), S. Raoul (N); Nice: V. Mattei (PI, P), D. Fontaine (N), M. Borg (NI), P. Paquis (NI), E. Michel (Np), P. Robert (P); E. Michel, F. Papetti (P); Paris Sainte-Anne Hospital: N. Baup (PI, P), B. Devaux (N), M.O. Krebs (P), C. Oppenheimer (R); J.P. Olié (P), D. Ranoux (NI), M. Chayet (Np); Poitiers: J.L. Houeto (PI, NI), N. Jaafari $(\mathrm{P})$, B. Bataille (N), V. Mesnage (NI); R. Gil (NI), V. Audouin $(\mathrm{Np})$, J.L. Senon (P); Rennes: B. Millet (PI, P), M. Vérin (NI), D. Drapier (P), P. Sauleau (E); S. Drapier (NI); Toulouse: C. Arbus (PI, P), Y. Lazorthe (N), P. Chaynes (N), N. Fabre (NI), M. Simonetta (E), L. Schmitt (P), J.A. Lotterie (R), C. Camassel. Sponsor: N. Best (Assistance Publique-Hôpitaux de Paris, Direction de la Recherche Clinique, Paris).

Independent Safety Committee: J.C Aussilloux, S. Blond, J. Feingold, D. Sicard. Independent Selection Committee: J. Adès, J. Cottraux, M. Goudemand. 